\title{
Factors predicting early discontinuation of exclusive breastfeeding in the first month of life
}

\author{
Graciete 0 . Vieira, ${ }^{1}$ Camilla da C. Martins, ${ }^{2}$ Tatiana de 0. Vieira, ${ }^{3}$ \\ Nelson F. de Oliveira, ${ }^{4}$ Luciana R. Silva ${ }^{5}$
}

\begin{abstract}
Objective: To investigate factors associated with discontinuation of exclusive breastfeeding in the first month of lactation, in the city of Feira de Santana, Brazil.

Methods: Cohort study with follow-up of 1,309 mother-child pairs selected from all maternities in the municipality. Data were collected in hospital and in home visits during the first month of life. Logistic regression analysis was used to examine the relationship between outcome and variables of interest.

Results: Lack of prior breastfeeding experience (PR 1.24; 95\%CI 1.75-1.43), cracked nipples (PR 1.25; $95 \%$ CI 1.09-1.43), use of fixed breastfeeding schedules (PR 1.42; 95\%CI 1.09-1.84) and pacifier use (PR 1.53; 95\%CI 1.34-1.76) were identified as factors predicting discontinuation of exclusive breastfeeding.

Conclusions: Measures to prevent early discontinuation of exclusive breastfeeding must focus on women without breastfeeding experience and include prevention of nipple trauma, encourage breastfeeding on demand, and discourage the use of pacifiers.
\end{abstract}

J Pediatr (Rio J). 2010;86(5):441-444: Breastfeeding, risk factors, weaning.

\section{Introduction}

Despite the importance and recommendation of exclusive breastfeeding in the first 6 months of an infant's life, ${ }^{1}$ this breastfeeding pattern is still little used in Brazil. ${ }^{2}$ Various factors have been implicated in the early discontinuation of exclusive breastfeeding, such as lack of prior breastfeeding experience, ${ }^{3,4}$ insufficient milk output, ${ }^{3,4}$ cracked nipples, ${ }^{5}$ pacifier use, ${ }^{4-7}$ and establishment of fixed breastfeeding schedules. ${ }^{1}$
In the municipality of Feira de Santana, state of Bahia, ${ }^{8}$ the prevalence of exclusive breastfeeding in the first month of life decreased from $75.8 \%$ in 1996 to $62.1 \%$ in 2001; however, the factors associated with the non-adoption of this practice have yet to be identified. In light of this scenario the present study sought to identify factors predicting discontinuation of exclusive breastfeeding in the first month of life in this municipality.

1. Doutora, Medicina e Saúde, Universidade Estadual de Feira de Santana (UEFS), Feira de Santana, BA, Brazil.

2. Mestre, Saúde Coletiva, UEFS, Feira de Santana, BA, Brazil.

3. Mestre, Medicina e Saúde. Universidade Federal da Bahia (UFBA), Salvador, BA, Brazil. UEFS, Feira de Santana, BA, Brazil.

4. Doutor, Estatística, UEFS, Feira de Santana, BA, Brazil.

5. Pós-Doutora, Centre Hospitalier de Bicêtre, Université Paris V, Paris, França. UFBA, Salvador, BA, Brazil.

No conflicts of interest declared concerning the publication of this article.

Suggested citation: Vieira GO, Martins CC, Vieira TO, de Oliveira NF, Silva LR. Factors predicting early discontinuation of exclusive breastfeeding in the first month of life. J Pediatr (Rio J). 2010;86(5):441-444.

Financial support: Fundação de Amparo à Pesquisa do Estado da Bahia (FAPESB).

Manuscript received Nov 13 2009, accepted for publication Apr 132010.

doi:10.2223/JPED.2010 


\section{Methods}

This was a cohort study of mother-child pairs from the municipality of Feira de Santana who have been followed since 2004 in order to assess the incidence and risk factors of lactation mastitis and other short- and medium-term breastfeeding-related outcomes. The present article reports the results of our analysis of the factors determining early discontinuation of exclusive breastfeeding. Data were collected at maternity units, in the 72 hours immediately following delivery, and in an initial home visit conducted at the end of the first month of infant life (between the 27th and 30th day postpartum).

The sample included all women seen over a period of 2 consecutive months in all 10 maternity units in the municipality. Women were added to the cohort over a 12month period; two hospitals, chosen by lots, were added every 2 months, with the exception of two units that were added separately because they served a greater number of patients.

Women who freely consented to taking part in the study were interviewed (one-on-one) by health professionals trained in data collection and breastfeeding management (nurse technicians and research assistants). Our inclusion criteria limited the sample to nursing mothers, living in Feira de Santana, who had had no gestational or postpartum complications that would contraindicate breastfeeding and whose newborn children had had no perinatal complications and/or had spent no more than 12 hours under observation or treatment at the hospital nursery. Data were collected for 1,309 mother-child pairs. No pairs were lost to followup during the first month of infant life.

The main study variables were birth weight (measured in grams), recorded in the infant's Caderneta de Saúde da Criança or medical record and simplified, for the purposes of this study, into $<2,500$ grams or $\geq 2,500$ grams; pacifier use (yes or no); prior breastfeeding experience (yes or no); breastfeeding in the first hour of life (yes or no); breastfeeding on demand (yes or no), recorded as "no" when the mother fed the child on a fixed schedule; and cracked nipples or nipple trauma, recorded when the mother reported nipple lacerations. ${ }^{5}$ Infants were considered exclusively breastfed when fed exclusively on mother's milk, including pumped breast milk. The only other permitted oral intakes were oral rehydration salts, vitamin supplements, or medication. ${ }^{9}$

Initially, all variables of interest were tested one by one with the outcome variable; those with a significance level of $25 \%$ ( $p<0.25$ ) were selected for the subsequent step. The second step consisted of building a model with all variables preselected at the previous step and conducting backward elimination with selection level $17 \%$ ( $p<0.17)$; the final model was then run with the variables selected at this step, again in backward elimination mode, at significance level
$5 \%(p<0.05)$; we then determined regression coefficients, odds ratios, and $95 \%$ confidence intervals. Calculations were performed in the SPSS 9.0 and R 2.8.0 statistical software suites.

This study was authorized by the Research Ethics Committee of the Universidade Estadual de Feira de Santana, registration number 080/2007, and supported by a grant from the Bahia Research Foundation (Fundação de Amparo à Pesquisa do Estado da Bahia).

\section{Results}

The prevalence of exclusive breastfeeding as determined in the present study was $96.9 \%(n=1,268)$ in the first 24 hours of life and $59.3 \%$ (776) by the end of the first month of life.

Sample characteristics and bivariate analysis results are shown in Table 1. Multivariate analysis showed that lack of prior breastfeeding experience, establishment of fixed breastfeeding schedules, pacifier use, and cracked nipples were associated with increased risk of discontinuing breastfeeding in the first month of life $(24,42,53$, and $25 \%$ greater risk respectively) (Table 2 ).

\section{Discussion}

In light of the excellence of exclusive breastfeeding and the decrease in this breastfeeding practice in the municipality of Feira de Santana, the present study is particularly relevant, as it sought to pinpoint the factors associated with early discontinuation of exclusive breastfeeding.

Four of the tested variables were associated with very early discontinuation of exclusive breastfeeding (that is, in the first month of life): establishment of fixed breastfeeding schedules, lack of prior breastfeeding experience, pacifier use, and cracked nipples.

Similar results were reported in previous studies conducted with the same objective and including these same variables as risk factors. ${ }^{3-5}$

As far as fixed breastfeeding schedules are concerned, the importance of on-demand breastfeeding as a facilitator of breastfeeding itself and of breast milk production is well documented in the literature. ${ }^{1}$

The association between longer duration of breastfeeding and prior breastfeeding experience, which had also been reported in other studies, 3,10 is likely due to the possibility that the breastfeeding experience itself has a positive impact on the mother's future decision to breastfeed and improves breastfeeding performance. However, other researchers have warned that prior breastfeeding experience is no guarantee that subsequent children will be breastfed, as each birth occurs in a different context. ${ }^{10}$ 
Table 1 - Results of bivariate analysis testing for association between selected variables and discontinuation of exclusive breastfeeding in the first month of lactation

\begin{tabular}{|c|c|c|c|}
\hline \multirow[b]{2}{*}{ Variables } & \multicolumn{2}{|c|}{ Exclusive breastfeeding } & \multirow[b]{2}{*}{$\mathbf{p}$} \\
\hline & Yes/n (\%) & No/n (\%) & \\
\hline \multicolumn{4}{|c|}{ Birth weight ( $n=1,309$ ) } \\
\hline$<2,500 \mathrm{~g}$ & $41(65.1)$ & $22(34.9)$ & \\
\hline$\geq 2,500 \mathrm{~g}$ & $735(59.0)$ & $511(41.0)$ & 0.337 \\
\hline \multicolumn{4}{|c|}{ Pacifier use $(n=1,309)$} \\
\hline Yes & $261(48.1)$ & $282(51.9)$ & \\
\hline No & $515(67.2)$ & $251(32.8)$ & 0.000 \\
\hline \multicolumn{4}{|c|}{ Prior breastfeeding experience $(n=1,309)$} \\
\hline No & $369(54.5)$ & $308(45.5)$ & \\
\hline Yes & $407(64.4)$ & $225(35.6)$ & 0.000 \\
\hline \multicolumn{4}{|c|}{ Breastfeeding in the first hour of life $(n=1,309)$} \\
\hline No & $413(59.6)$ & $280(40.4)$ & \\
\hline Yes & $363(58.9)$ & $253(41.1)$ & 0.806 \\
\hline \multicolumn{4}{|c|}{ Cracked nipples ( $\mathrm{n}=1,309$ ) } \\
\hline Yes & $246(52.6)$ & $222(47.4)$ & \\
\hline No & $530(63.0)$ & $311(37.0)$ & 0.000 \\
\hline \multicolumn{4}{|c|}{ Fixed breastfeeding schedules $(n=1,289)$} \\
\hline Yes & $23(42.6)$ & $31(57.4)$ & \\
\hline No & $753(61.0)$ & $482(39.0)$ & 0.007 \\
\hline
\end{tabular}

The use of pacifiers is one of the factors most consistently associated with early discontinuation of breastfeeding in the literature, having been described in several studies $4,7,11$ as a factor associated with decreased duration of exclusive breasfeeding. 4,6,7 Nonetheless, the factors underlying this association are not yet fully understood. The use of a pacifier likely decreases the number of daily feedings, consequently decreasing stimulation of the nipple-areola complex and milk production, ultimately leading to the need for supplemental feeding. 4,6,7 Other authors suggest that the pacifier itself is not the primary cause of weaning, but rather an indicator of the mother's wish to wean ${ }^{12}$ or a sign of difficulty breastfeeding. ${ }^{13}$

Finally, a positive association between cracked nipples and early discontinuation of exclusive breastfeeding has also been reported elsewhere, ${ }^{3,14,15}$ although it is not unanimous. ${ }^{4}$ One must take into account that cracked nipples are most common in the first few months of lactation, during which

Table 2 - Results of logistic regression testing for association between selected variables and discontinuation of exclusive breastfeeding in the first month of lactation

\begin{tabular}{|c|c|c|c|c|}
\hline Variables & Crude OR & $95 \% \mathrm{CI}$ & Adjusted OR & $95 \% \mathrm{CI}$ \\
\hline \multicolumn{5}{|c|}{ Prior breastfeeding experience } \\
\hline No & 1.28 & $1.12-1.46$ & 1.24 & $1.75-1.43$ \\
\hline Yes & 1.0 & & 1.0 & \\
\hline \multicolumn{5}{|c|}{ Fixed breastfeeding schedules } \\
\hline Yes & 1.47 & $1.16-1.87$ & 1.42 & $1.09-1.84$ \\
\hline No & 1.0 & & 1.0 & \\
\hline \multicolumn{5}{|l|}{ Pacifier use } \\
\hline Yes & 1.58 & $1.39-1.80$ & 1.53 & $1.34-1.76$ \\
\hline No & 1.0 & & 1.0 & \\
\hline \multicolumn{5}{|c|}{ Cracked nipples } \\
\hline Yes & 1.28 & $1.13-1.46$ & 1.25 & $1.09-1.43$ \\
\hline No & 1.0 & & 1.0 & \\
\hline
\end{tabular}

$95 \% \mathrm{Cl}=95 \%$ confidence interval; OR = odds ratio. 
breastfeeding practices are being established; the causes of this condition must therefore be identified for possible intervention and prevention of early weaning. Consequently, follow-up studies should be conducted to investigate the etiology of cracked nipples.

Although the results of the present study are consistent with those reported by other researchers, they are highly relevant, as they strengthen the established knowledge base and serve as a bearing for planning of local actions. Measures seeking to prevent early discontinuation of exclusive breastfeeding in the municipality of Feira de Santana should thus place a priority focus on women with no prior breastfeeding experience, provide for the prevention of nipple trauma, encourage breastfeeding on demand, and discourage pacifier use.

\section{References}

1. World Health Organization (WHO). Infant and young child feeding: model chapter for textbooks for medical students and allied health professionals. Geneva: WHO; 2009.

2. Brasil. Ministério da Saúde. II Pesquisa de Prevalência de Aleitamento Materno nas Capitais Brasileiras e Distrito Federal. Brasília: Editora do Ministério da Saúde; 2009.

3. Ramos CV, Almeida JA. Alegações maternas para o desmame: estudo qualitativo. J Pediatr (Rio J). 2003;79:385-90.

4. Santo LC, de Oliveira LD, Giugliani ER. Factors associated with low incidence of exclusive breastfeeding for the first 6 months. Birth. 2007;34:212-9.

5. Ahluwalia IB, Morrow B, Hsia J. Why do women stop breastfeeding? Findings from the Pregnancy Risk Assessment and Monitoring System. Pediatrics. 2005; 116:1408-12.

6. Chaves RG, Lamounier JA, César CC. Factors associated with duration of breastfeeding. J Pediatr (Rio J). 2007;83:241-6.
7. Castilho SD, Rocha MA. Pacifier habit: history and multidisciplinary view. J Pediatr (Rio J). 2009;85:480-9.

8. Vieira GO. Alimentação infantil e morbidade por diarréia na cidade de Feira de Santana [dissertação]. Feira de Santana: Universidade Estadual de Feira de Santana; 2002.

9. World Health Organization (WHO). Indicators for assessing infant and young child feeding practices. Geneva: WHO Library Cataloguing-in-Publication Data; 2007.

10. Faleiros FT, Trezza EM, Carandina L. Aleitamento materno: fatores de influência na sua decisão e duração. Rev Nutr. 2006;19:623-30.

11. Pansy J, Zotter H, Sauseng W, Schneuber S, Lang U, Kerbl R. Pacifier use: what makes mothers change their mind? Acta Paediatr. 2008;97:968-71.

12. Silveira FJ, Lamounier JA. Fatores associados à duração do aleitamento materno em três municípios na região do Alto Jequitinhonha, Minas Gerais, Brasil. Cad Saude Publica. 2006;22:69-77.

13. Coutinho SB, Lima MC, Ashworth A, Lira PI. Impacto de treinamento baseado na Iniciativa Hospital Amigo da Criança sobre práticas relacionadas à amamentação no interior do Nordeste. J Pediatr (Rio J). 2005;81:471-7.

14. Cooke M, Sheehan A, Schmied V. A description of the relationship between breastfeeding experiences, breastfeeding satisfaction, and weaning in the first 3 months after birth. J Hum Lact. 2003; 19:145-56.

15. Centouri S, Burmaz T, Ronfani L, Fragiacomo M, Quintero $S$, Pavan C, et al. Nipple care, sore nipples, and breastfeeding: a randomized trial. J Hum Lact. 1999;15:125-30.

Correspondence:

Graciete O. Vieira

Rua Barão do Rio Branco, 1499 - Centro

CEP 44001-205 - Feira de Santana, BA - Brazil

Tel.: +55 (75) $3221.3884,+55$ (75) 9977.5486

Fax: +55 (75) 3223.2351

E-mail: gracietevieira@terra.com.br 